\title{
Exploring The Impact Of Use And Non-Use Value On Behavioral Intention To Purchase Organic Foods: Evidence From A Developing Country's Context
}

\author{
Nor Azila Mohd Noor*, Khandoker Mahmud
}

Othman Yeop Abdullah Graduate School of Business, Universiti Utara Malaysia, 06010 UUM Sintok, Kedah, Malaysia

*Corresponding author: azila@uum.edu.my

\begin{abstract}
A number of determinants have been investigated by past researchers in the framework of theory of planned behavior. In addition to attitude, subjective norm and perceived behavioral control, use and non-use values have been studied by past researchers with inconsistent results. This article is aimed at identifying the impact of 'use' and 'non-use' values on organic food purchase intention in a developing country's context like Bangladesh. Some past studies found both the values significant, whereas some studies found only use-values as dominant determinant in the consumer decision making process. The current study is aimed at exploring the impact of both the use and non-use values simultaneously on the purchase intention of organic foods. The study employs the theory of planned behavior as the research framework to investigate the impact of these values on intention. Partial least-square structural equation modeling (PLSSEM) was adopted. Results showed that both the values were significant predictor of purchase intention along with attitude and subjective norm (SN). Perceived behavior control (PBC) appeared to be non-significant relationship. Although both the use and non-use values appear to be important in determining consumer intention, use-value carries higher impact compared to non-use value.
\end{abstract}

Keywords: Use value; non-use value; organic food purchase intention; theory of planned behavior.

(C) 2016 Penerbit UTM Press. All rights reserved

\subsection{INTRODUCTION}

Theory of planned behavior has been extensively used in explaining the organic food purchase intention by past researchers. In addition to the core predictors of the model, a number of variables were proposed and investigated in order to explain determinants of organic food related intention and behavior. Some of these investigations included value motivation of consumers in order to account for the influence of consumers' use and non-use values behind their purchase motivation (Gschwandtner \& Gschwandtner, 2014; Millock, Wier, \& Andersen, 2004; Wier et al., 2008). These values can be explained from the background attributes of private goods and public goods. For example, private goods can only be used by one household or individual (e.g., an organic potato), whereas public goods can be shared in the society, such that the utility of their consumption by any one household does not exclude consumption by other households (Wier et al., 2008). 'Use value' primarily comes from the utility of taste, health and freshness, i.e. private good characteristics, which can only be enjoyed by consuming the product. On the other hand, 'non-use values' are seen as public goods characteristics like the shared positive outcome of improved environment and/or social harmony.

There could be other non-use values as well. For example, existence value (utility from knowing that organic cultivation exists), vicarious value (utility from indirect consumption, e.g. knowing more about organic farming), bequest value (utility from preserving organic farming for subsequent generations), etc. (Millock, Wier, \& Andersen, 2004a). However, for the purpose of this paper, only 'use' and 'nonuse' values are considered as it would be out of scope and extend beyond a manageable scale to consider all the use and non-use values in a single write-up. Therefore, health motivation factors in organic purchase intention are regarded as use-value; whereas environmental factors are treated as non-use value for this study, as these values appear to be the most dominant values in purchase motivation or intention (Millock et al., 2004a; Wee, 2014).

\subsection{LITERATURE REVIEW}

As already noted, use value consists of health value, taste, freshness, etc. Among these use values, health value has received consistently high ranking in past empirical studies (Millock et al., 2004a; Paul \& Rana, 2012). Other studies also mentioned similar results that health concern is an important driving factor for organic consumers (Magnusson et al., 2003; Kesse-Guyot et al., 2013). Such a positive association of organic food with health perception may stem from the fact that organic foods do not contain any pesticide residue, and some foods are more nutritious than genetically modified foods (Crinnion, 2010). In certain studies, health concern has been so influential that non-use values like environmental concern and animal welfare appeared to be insignificant (Millock et al., 2004a; Samarasinghe, 2012). However, some studies found opposite results. Certain non-use values like environmental issues, animal welfare, etc. appear to be important by some 
researchers (Wier et al., 2008). Among these non-use values, environmental concern has been found to be significantly related to organic food consumer behavior (Rodríguez, Roig, \& Font, 2011).

In general, a positive attitude to ecological issues is positively identified with the organic food consumers' motivation (Grunert \& Juhl, 1995). Among the TPB constructs that consistently showed significance to purchase intention is Attitude. Past studies found that attitude has significant bearing on purchase intention of organic foods or eco-friendly products (Boomsma, 2012; Zhou, 2013). Other researchers also corroborated such findings (Saleki, Seyedsaleki, \& Rahimi, 2012). Similar positive association were found between subjective norm (SN) and purchase intention (Smith \& Paladino, 2010). Particularly in the Asian context, most studies found that subjective norm has been consistently a significant predictor of organic food purchase intention (Rahman \& Noor, 2016). However, results for perceived behavioral control (PBC) has been somewhat mixed. While some studies found significant link between PBC and purchase intention (Azam, Othman, Musa, AbdulFatah, \& Awal, 2012; Choi \& Kim, 2005), some others found no significance of this construct (Rahman \& Noor, 2016; Ščasný, Urban, \& Zvěřinová, 2012). It appears that PBC may be considered in the model to be proposed for further empirical scrutiny.

\subsection{CONCEPTUAL FRAMEWORK}

Based on the literature survey, it appears that TPB could be adopted as the core theoretical framework, to be modified by including the 'use' and 'non-use' values. In fact, these values can be seen as dimensions of a greater 'value' construct and studied in the model. As past researchers found that 'value' could be a predictor of purchase intention (Chen, Shang, Shu, \& Lin, 2015), a direct positive relationship with purchase intention may be assumed in the TPB framework. Therefore, the conceptual framework is depicted in Figure 1.

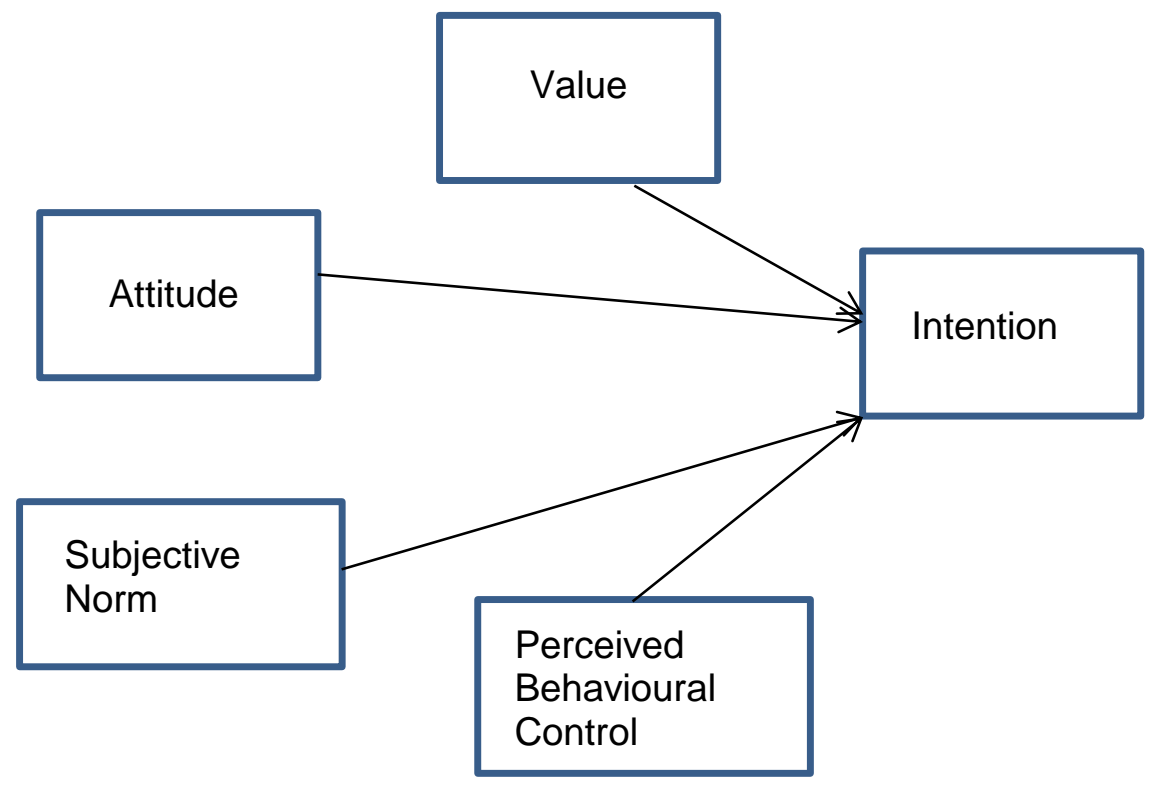

Figure 1 Conceptual Framework

As already noted, the value construct would be viewed as a two-dimensional measure (use and non-use values), whereas all other constructs are uni-dimensional. Therefore, hypotheses are drawn as presented in Table 2.

\subsection{METHODOLOGY}

The study is causal and quantitative in nature, attempting to identify the influence of 'value' in the TPB framework. Latent variable modeling approach was used by using multi-item measurements from existing scales. A questionnaire was developed based on these multi-item measurements. Intention was measured by a 5-item scale adapted from Chan (2001) and Tseng and Tsai (2011). Value was measured in two-dimensions, i.e., 'use' and 'non-use' value. Use-value was measured by a 3-item scale, by adapting from the health concern scale used by Chen (2009) and Magnusson et al. (2003). On the other hand, "non-use" value was measured by a 3-item scale, modified and adapted from Magnusson et al. (2003). Attitude was measured by a 5-item scale adapted from the scale proposed by Arvola et al. (2008) and Crites et al. (1994). Other remaining constructs- Subjective Norm and PBC, both used 4-item scales, developed from Arvola et al. (2008) and Courneya, Bobick, and Schinke (1999) respectively. Partial Least-square Structural Equation Modeling (PLS-SEM) was used in evaluating the proposed model. In this process of deciding on scales, it is important to identify if the indicators are of reflective or formative in nature. While formative indicators add to the formation of a construct and exhaustive in nature, reflective indicators characterize a construct and are unidirectional. Reflective indicators may not be exhaustive as other indicators might be left out in the model. Thus formative indicators are not assumed to be correlated whereas reflective constructs are assumed to be highly correlated with each other (Chin, 1998). For the purpose of this study, all indicators are assumed to be reflective since items and dimensions are not definitive in nature. Sampling was conducted in Dhaka, the Capital of Bangladesh, where $95 \%$ of organic food retailers in Bangladesh are located. Mall intercept technique based on 
systematic random method was used based on established practices among marketing researchers (Beri, 2013). After screening for outliers, incomplete and invalid responses, 322 samples were kept for further analysis. The following section presents the research findings.

\subsection{RESULTS AND DISCUSSION}

The analysis of data was conducted by using SmartPLS3, by using two-stage procedure as recommended by SmartPLS literature (Garson, 2016). Thus, the measurement model is presented to be followed by structural model. It may be mentioned that, some of the indicators were deleted to conform to the item-loading cut-off point of 0.6 or above (Hair et al., 2014). Factor loadings are shown in Appendix 1, and are not shown in the table 1 for the purpose of brevity. The following table shows results for the measurement model.

Table 1 Cronbach alpha, Composite Reliability (CR) and AVE

\begin{tabular}{lccc}
\hline \multicolumn{1}{c}{ Construct } & Cronb. $\alpha$ & CR & AVE \\
\hline Use-value & & & 0.644 \\
Non-use value & 0.724 & 0.845 & 0.607 \\
Attitude & 0.700 & 0.822 & 0.501 \\
Subjective Norms & 0.702 & 0.798 & 0.674 \\
PBC & 0.728 & 0.846 & 0.576 \\
Intention & 0.710 & 0.800 & 0.502 \\
\hline
\end{tabular}

While there are many cut-off values for Cronbach alphas and Composite Reliability (CR) as recommended by past scholars, it is widely popular to use 0.70 for both the measures based on Nunnally and Bernstein (1994) and Hair et al. (2014). Table 1 summarizes the reported values shows that all the indicators (CR and Cronbach alpha values) are within this cut-off limit. In addition, AVE values have met the minimum criteria of 0.50 (Henseler et al., 2009). Based on these findings, it is assumed that convergent validity is established. In addition, Heterotrait-Monotrait (HTMT) criteria was used to confirm discriminant validity (Henseler, Ringle, \& Sarstedt, 2015). It was recommended that the HTMT ratio be below 0.90 in order to indicate an acceptable level of discriminant validity (Henseler et al., 2015). It was found that the discriminant validity is achieved as all the ratios are well below 0.90 (not shown for brevity).

Next, the analysis of structural model shows that all the constructs are significant in the modeled relationship (Appendix 2). Table 2 shows the results of hypotheses testing based on the evaluation of structural model.

Table 2 Summary of hypothesis testing

\begin{tabular}{|c|l|c|c|c|c|}
\hline No. & Hypothesis & Path coefficients & t-value & p-value & Support \\
\hline H1a & Value positively affects Intention & 0.328 & 5.641 & 0.000 & Yes $* * *$ \\
\hline H1b & Attitude positively affects Intention & 0.165 & 2.862 & 0.002 & Yes $* * *$ \\
\hline H1c & SN positively affects Intention & 0.193 & 2.987 & 0.001 & Yes \\
\hline H1d & PBC positively affects Intention & 0.016 & 0.257 & 0.398 & No \\
\hline Note: & (i) One-tailed test at alpha $=0.05$ \\
& (ii) $* * *=$ significant at alpha 0.01
\end{tabular}

Therefore, it appears that the implication of 'use' and 'non-use' values are significant in determining purchase intention as evident from the empirical analysis. From measurement model, it seems that use-value (health benefits) has higher impact than non-use value (environmental benefits) in the overall "Value" construct. This conforms to past findings that use-value is more influential than non-use values (Millock et al., 2004a). It implies that, although consumers are aware about environmental benefits, it is more of private goods attributes that drive their intention. Marketers may note its implications while designing future marketing programs. In addition, the findings that attitude and subjective norm significantly impacts purchase intention also conform to many past studies in this regards. The low R-square value of 0.278 indicates that many other variables might be at play that needs further evaluation. However, non-significance of PBC is interesting as it appears to conform with studies that found no significant relationship of the construct with purchase intention (Ščasný, Urban, \& Zvěřinová, 2012).

\subsection{CONCLUSION}

The model suggests that 'use' and 'non-use' values are important determinants of purchase intention. Marketers may use this information in their future marketing programs to align their strategy to customers' value expectations. Non-significance of PBC can be noted as well, which means that consumers' purchase intention could be independent of the perceived behavioral control of consumers. In addition, the low R-square value may imply that other variables need to be considered to account for unexplained variation in the intention. Overall, the significant model fit yields a set of useful information both for academicians and marketing practitioners. 


\section{References}

Arvola, A., Vassallo, M., Dean, M., Lampila, P., Saba, A., Lähteenmäki, L., \& Shepherd, R. (2008). Predicting Intentions To Purchase Organic Food: The Role Of Affective And Moral Attitudes in the Theory of Planned Behaviour. Appetite, 50, (2-3), 443-54.

Azam, N. H. M., Othman, N., Musa, R., AbdulFatah, F., \& Awal, A. (2012). Determinants Of Organic Food Purchase Intention. 2012 IEEE Symposium on Business, Engineering and Industrial Applications, 748-753

Beri, G. C. (2013). Marketing Research. Tata: McGraw-Hill.

Chan, R. (2001). Determinants Of Chinese Consumers' Green Purchase Behavior. Psychology \& Marketing, 18, (April 2001), 389-413.

Chen, M.-F. (2009). Attitude Toward Organic Foods Among Taiwanese As Related To Health Consciousness, Environmental Attitudes, And The Mediating Effects Of A Healthy Lifestyle. British Food Journal, 111(2), 165-178.

Chen, Y.-C., Shang, R.-A., Shu, C.-Y., \& Lin, C.-K. (2015). The Effects of Risk and Hedonic Value on the Intention to Purchase on Group Buying Website: The Role of Trust, Price and Conformity Intention. Universal Journal of Management, 3(6), 246-256.

Chin, W. W. (1998). The Partial Least Squares Approach To Structural Equation Modeling. Modern Methods for Business Research, 295(2), 295-336.

Choi, M., \& Kim, Y. (2005). Antecedents Of Green Purchase Behavior: An Examination Of Collectivism, Environmental Concern, and PCE. Advances in Consumer Research, 592-599.

Courneya, K. S., Bobick, T. M., \& Schinke, R. J. (1999). Does the Theory of Planned Behavior Mediate the Relation Between Personality and Exercise Behavior? Basic and Applied Social Psychology, 21(4), 317-324.

Crinnion, W. J. (2010). Organic Foods Contain Higher Levels Of Certain Nutrients, Lower Levels Of Pesticides, And May Provide Health Benefits For The Consumer. Alternative Medicine Review : A Journal of Clinical Therapeutic, 15(1), 4-12.

Crites, S., Fabrigar, L., \& Petty, R. (1994). Measuring The Affective And Cognitive Properties Of Attitudes: Conceptual And Methodological Issues. Personality and Social Psychology Bulletin, 20(6), 619-634.

Garson, G. D. (2016). Partial Least Squares: Regression \& Structural Equation Models. Asheboro: Statistical Associates Publishing.

Grunert, S., \& Juhl, H. (1995). Values, Environmental Attitudes, And Buying Of Organic Foods. Journal of Economic Psychology, 16(1995), 39-62.

Gschwandtner, A., \& Gschwandtner, A. (2014). The Organic Food Premium : A Canterbury Tale The Organic Food Premium : A Canterbury Tale.

Hair Jr, J. F., Hult, G. T. M., Ringle, C. M., \& Sarstedt, M. (2014). A Primer On Partial Least Squares Structural Equation Modeling (PLS-SEM). SAGE Publications, Incorporated.

Henseler, J., Ringle, C. M., \& Sarstedt, M. (2015). A New Criterion For Assessing Discriminant Validity In Variance-Based Structural Equation Modeling. Journal of the Academy of Marketing Science, 43(1), 115-135.

Henseler, J., Ringle, C. M., \& Sinkovics, R. R. (2009). The Use Of Partial Least Squares Path Modeling In International Marketing. Advances in International Marketing, $20,277-319$.

Kesse-Guyot, E., Péneau, S., Méjean, C., Szabo de Edelenyi, F., Galan, P., Hercberg, S., \& Lairon, D. (2013). Profiles Of Organic Food Consumers In A Large Sample Of French Adults: Results From The Nutrinet-Santé Cohort Study. PloS One, 8(10), 22-28.

Magnusson, M. K., Arvola, A., Hursti, U.-K. K., Åberg, L., \& Sjödén, P.-O. (2003). Choice Of Organic Foods Is Related To Perceived Consequences For Human Health And To Environmentally Friendly Behaviour. Appetite, 40(2), 109-117.

Millock, K., Wier, M., \& Andersen, L. M. (2004a). Consumer Demand For Organic Foods - Attitudes, Values And Purchasing Behaviour. In 13th annual EAERE Conference, Budapest (pp. 1-4).

Nunnally, J. C., \& Bernstein, I. H. (1994). The Assessment Of Reliability. Psychometric Theory, 3, 248-292.

Paul, J., \& Rana, J. (2012). Consumer Behavior And Purchase Intention For Organic Food. Journal of Consumer Marketing, 29(6), 412-422.

Rahman, K. M., \& Noor, N. A. M. (2016). Exploring Organic Food Purchase Intention in Bangladesh: An Evaluation by Using the Theory of Planned Behavior. International Business Management, 10(18), 4292-4300.

Rodríguez, A., Roig, J. G., \& Font, M. C. (2011). Structural Equation Modelling Of Consumer Acceptance Of Organic Food in Spain. In VIII Congreso de Economia Agraria (pp. 1-36).

Saleki, Z. S., Seyedsaleki, S. M., \& Rahimi, M. R. (2012). Organic Food Purchasing Behaviour in Iran. International Journal of Business and Social Science, 3(13), $278-285$.

Samarasinghe, R. (2012). The Influence of Cultural Values and Environmental Attitudes on Green Consumer Behaviour. International Journal of Behavioral Science, $7(1), 83-98$

Ščasný, M., Urban, J., \& Zvěřinová, I. (2012). What Motivates Czech Consumers to Buy Organic Food? Czech Sociological Review, 48(3), 709-737.

Smith, S., \& Paladino, A. (2010). Eating clean And Green? Investigating Consumer Motivations Towards The Purchase Of Organic Food. Australasian Marketing Journal (AMJ), (1980), 1-8

Tseng, C.-J., \& Tsai, S.-C. (2011). Effect of Consumer Environmental Attitude on Green Consumption Decision-Making. Pakistan Journal of Statistics, 27(5), 699708.

Wee, C. S. (2014). Consumers Perception, Purchase Intention and Actual Purchase Behavior of Organic Food Products. Review of Integrative Business \& Economics, 3(2), 378-397.

Wier, M., O'Doherty Jensen, K., Andersen, L. M., \& Millock, K. (2008). The Character Of Demand In Mature Organic Food Markets: Great Britain and Denmark Compared. Food Policy, 33(5), 406-421.

Zhou, Y. (2013). The Moderating Role Of Human Values In Planned Behavior: The Case Of Chinese Consumers' Intention To Buy Organic Food. Journal of Consumer Marketing, 30(4), 335-344. 
Appendix 1: Measurement Model

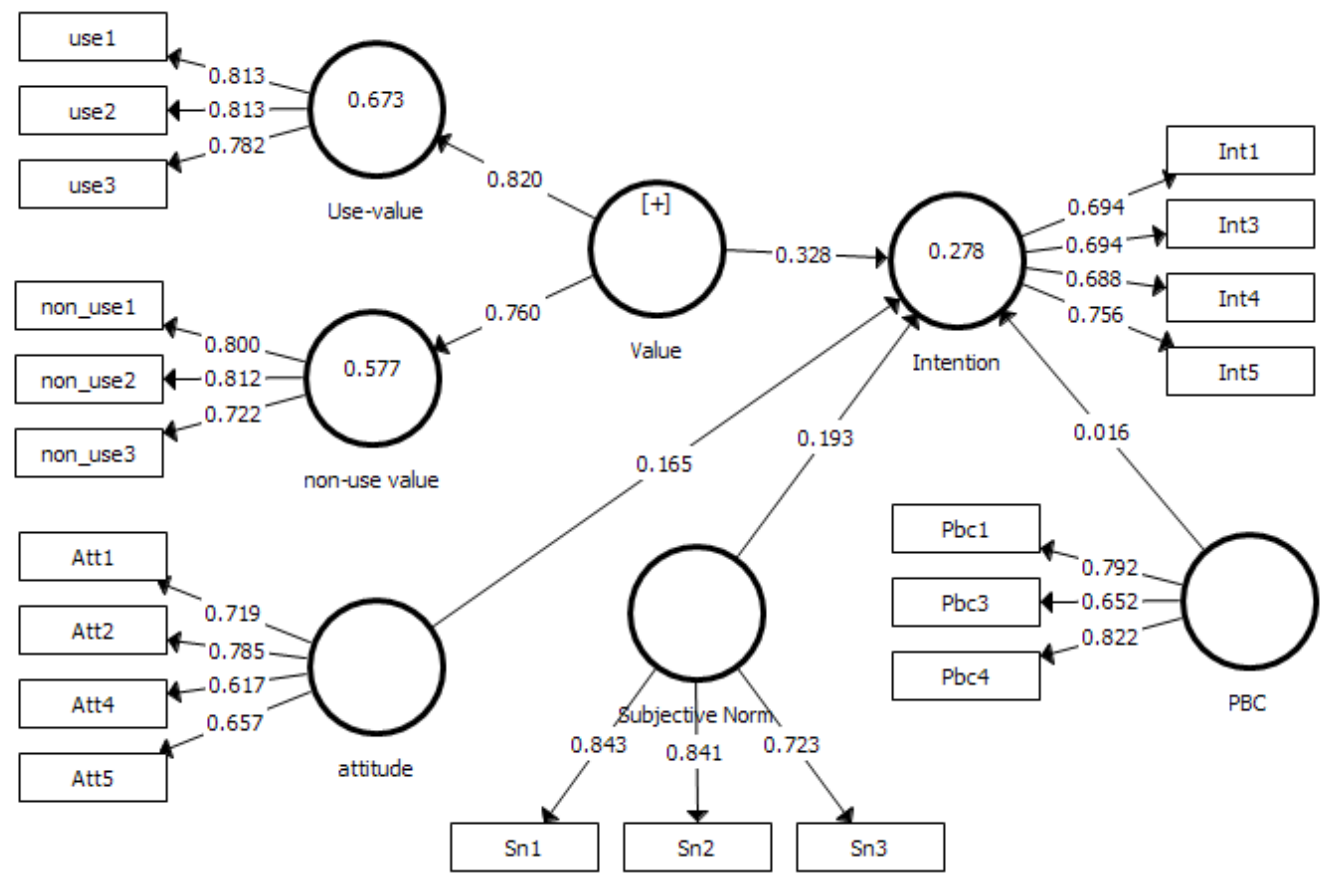

Appendix 2: Measurement Model

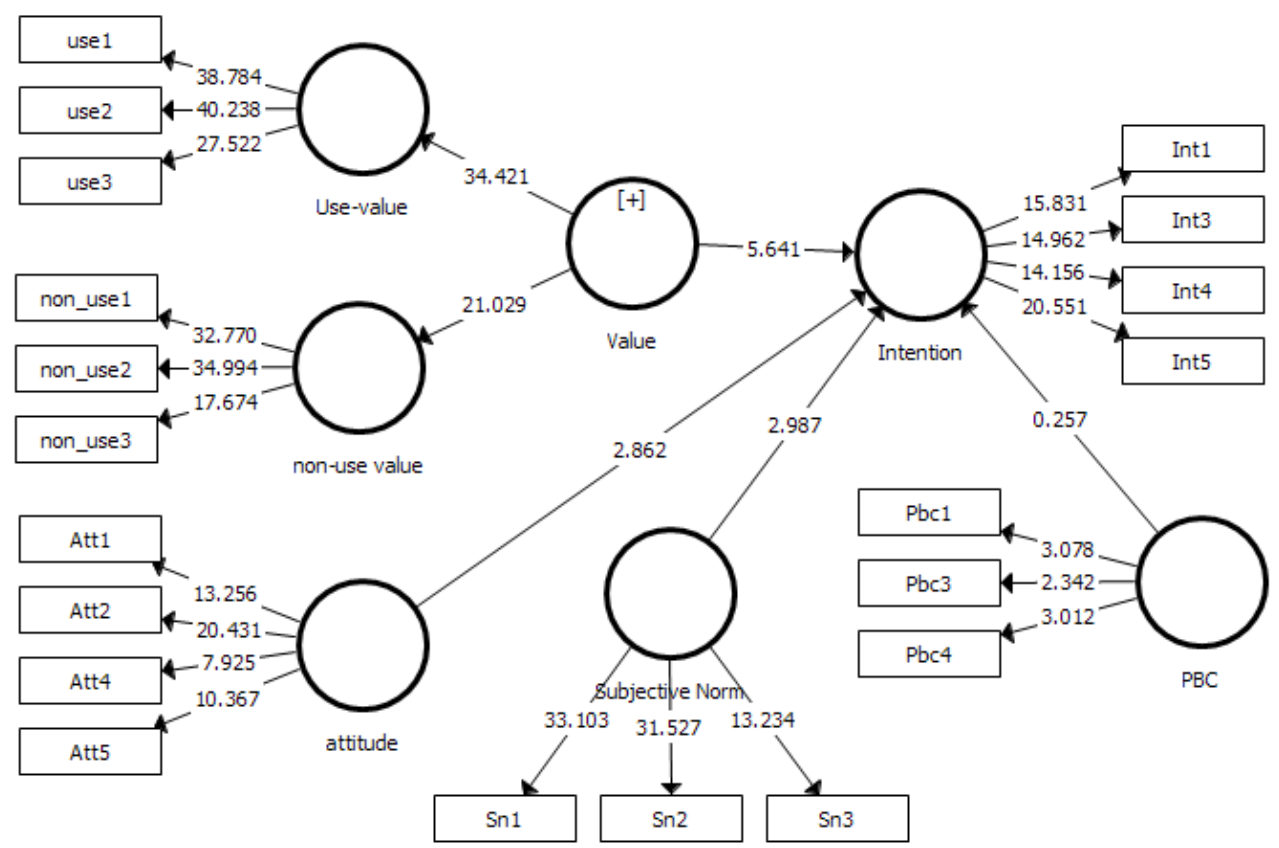

